\title{
Orthometric height connection across sea with ship- borne gravimetry and GNSS measurement along the ship route
}

\author{
Jianbo Wang ${ }^{1} \cdot$ Jinyun Guo ${ }^{1,2} \cdot$ Xin Liu ${ }^{1} \cdot$ \\ Qiaoli Kong ${ }^{1,2} \cdot$ Yi Shen ${ }^{1} \cdot$ Yu $\operatorname{Sun}^{3}$
}

Received: 10 November 2015/Accepted: 5 May 2016/Published online: 23 May 2016

(C) Akadémiai Kiadó 2016

\begin{abstract}
A new method is proposed to connect the orthometric height datum of island far from mainland with measurements of both ship-borne gravimetry and GNSS along the ship route connecting these datums. The methodology of route height datum connection is based on the astronomical leveling principle. The effect of the deflection of the vertical (DOV) error and the ellipsoidal height difference error are major factors on the precision of the orthometric height connection. To improve the computational accuracy of DOVs along the ship route, the collinear adjustment is used to improve the accuracy of the gravity measurements and GNSS ellipsoidal heights. The remove-restore technique in conjunction with the measured DOVs on the mainland and island is used to improve the estimation accuracy of the DOVs along the ship route. The least squares collocation method is used to estimate the residual DOVs. The covariance of gravity anomalies and cross-covariance function between gravity anomalies and DOVs are derived from the disturbing potential spherical harmonic expansion. The optimal partition number is also studied for the high precision orthometric height connection across sea. Finally, we use the proposed method to connect the orthometric height datum point on Qingdao coast in Shandong Province of China with the datum point on Caoyu coast in Fujian Province of China.
\end{abstract}

Keywords Orthometric height connection across sea - Deflection of the vertical - Shipborne gravimetry · Ship-borne GNSS measurement · Disturbing potential spherical harmonic expansion · Least squares collocation

Jinyun Guo

jinyunguo1@126.com

1 College of Geodesy and Geomatics, Shandong University of Science and Technology, Qingdao 266590, China

2 State Key Laboratory of Mining Disaster Prevention and Control Co-founded by Shandong Province and Ministry of Science \& Technology, Qingdao 266590, China

3 Department of Geoscience and Remote Sensing, Delft University of Technology, Delft, The Netherlands 


\section{Introduction}

The plane datum unification between mainland and island can be achieved to some extent due to the global navigation satellite system (GNSS). However, the theory and practice of height datum unification across sea still have some limitations. Because of the sea surface slope (Rummel and Teunissen 1988), the local mean sea level is not an equipotential surface and cannot be used in the height datum unification across sea. Traditionally, there are many methods practiced for height unification across sea, e.g. GPS leveling, geometric leveling, hydrostatic leveling, and trigonometric leveling method (Li and Jiang 2001). The accuracy of height differences from GPS leveling depends mainly on the accuracy of the underlying geoid model. The rather limited length of the sight-line between the level and the staff imposes restrictions on the use of the geometric leveling method for across sea measurements. Due to the refraction of the optical sight-line, the accuracy of trigonometric leveling method cannot be maintained for long distances. Hydrostatic leveling is a method to utilize an elastic tube filled with liquid laid over the water body to be bridged. Precise hydrostatic leveling is technically sophisticated because of the air-bubbles effects in the tube. This method is no longer feasible mainly due to its high cost and high sensitivity to temporal and spatial changes in the environmental condition (Liibusk 2013).

Various methods and theories, among which the key issue is how to determine the potential differences or height differences between different height datums, have been developed to unify or connect the height datum across sea. Because the mainland and the island are separated by the sea, it is impossible to directly measure the potential difference by the precise leveling in conjunction with gravimetry as commonly used on the mainland. Using the gravity field model and satellite altimetry information (Mather et al. 1978) or combining satellite and terrestrial data (Heck and Rummel 1990) can determine the potential differences of benchmarks thousands of kilometers away. These two methods depend primarily on the quality of the reference gravity field model. The solution of the linear geodetic boundary value problem (GBVP) can be used to determine the geoid height difference of vertical datums (Rummel and Teunissen 1988; Nahavandchi and Sjöberg 1998). However, this method requires the use of the local height datum to determine the gravity anomaly. The GOCE-geoid (Rummel 2012; Gerlach and Rummel 2013) combining with satellite altimetry or space positioning, geodetic leveling and modified GBVP can be used for the global height system unification. However, the solution requires the availability of at least one geodetic reference station with known orthometric height and ellipsoidal height. The solution of the linearized fixed-gravimetric boundary value problem can be used to determine the gravity potential difference between two local height datums (Sacerdote and Sanso 1989; Fei and Sideris 2001; Li et al. 2003; Yu et al. 2003; Zhang et al. 2009). This method needs more gravity data over large areas, and it can be much time-consuming and costly (Guo et al. 2014). The height datums can also be unified by determining the offset of vertical datums using gravimetric geoid combining with GPS data (Goldan and Seeber 1994; Kumar and Burke 1998; Pan and Sjöberg 1998; Pouttanen 1999) or by determining the offset between a local geoid and a global gravity potential model (Burša et al. 1999, 2001, 2004) using GPS/leveling data. Note that the gravimetric geoid still needs measurements over a reasonably large area to smooth the high frequency gravity components. Xu et al. (2009) proposed a virtual leveling method which uses gravity data and GNSS measurements with the same datum. This method uses the first difference of geoidal undulation rather than the absolute geoidal height when calculating the potential difference, which facilitates to remove the absolute error of the geoid degrading the 
precision of the height determination. But the global geoid model has a border effect near the coastlines because of the low quality of marine data and the differences between the terrestrial and oceanic gravity data. The global geoid model usually has systemic errors near the coastlines (Huang et al. 2005).

In this study, we aim to present a method to connect the long-distance height datums across sea based on the astronomical leveling principle. The methodology on orthometric height connection across sea and the possible parameter errors as well as their effects on the accuracy of orthometric height connection are discussed in Sect. 2. The deflection of the verticals (DOVs) along the ship route, which are computed based on the remove-restore technique and least squares collocation (LSC) method, are studied in Sect. 3. A case study using the proposed method is shown in Sect. 4. Finally, the study is briefly summarized in Sect. 5 .

\section{Methodology}

\subsection{Orthometric height connection across sea}

The fundamental formula for the astronomical leveling principle (Heiskanen and Moritz 1967) is

$$
\Delta \mathrm{N}_{\mathrm{AB}}=\mathrm{N}_{\mathrm{B}}-\mathrm{N}_{\mathrm{A}}=-\int_{\mathrm{A}}^{\mathrm{B}} \theta \mathrm{ds},
$$

where $\Delta \mathrm{N}_{\mathrm{AB}}$ is the geoid undulation difference between stations $\mathrm{A}$ and $\mathrm{B} . \mathrm{N}_{\mathrm{A}}$ and $\mathrm{N}_{\mathrm{B}}$ represent the geoid undulations of stations $\mathrm{A}$ and $\mathrm{B}$, respectively. $\mathrm{s}$ is the distance along the direction of $\mathrm{AB}$ in the geoid. $\theta$ is the $\mathrm{DOV}$ component along the direction of $\mathrm{AB}$ on the geoid, which can be written as

$$
\theta=\xi \cos \alpha+\eta \sin \alpha,
$$

in which $\xi$ and $\eta$ represent the meridian and prime vertical components of the DOV on the geoid respectively. $\alpha$ is the azimuth of AB. In Eq. (2), DOV is the value located on the geoid. However, DOVs cannot be measured on the geoid. Instead, they are measured on the ground and directly substituted into the astronomical leveling principle to compute the geoid undulation difference between $\mathrm{A}$ and $\mathrm{B}$, and the result is reduced to the geoid (Heiskanen and Moritz 1967) as following

$$
\Delta \mathrm{N}_{\mathrm{AB}}=-\int_{\mathrm{A}}^{\mathrm{B}} \theta \mathrm{ds}-\int_{\mathrm{A}}^{\mathrm{B}} \frac{\mathrm{g}-\gamma_{0}}{\gamma_{0}} \mathrm{dH}+\frac{\overline{\mathrm{g}}_{\mathrm{B}}-\gamma_{0}}{\gamma_{0}} \mathrm{H}_{\mathrm{B}}-\frac{\overline{\mathrm{g}}_{\mathrm{A}}-\gamma_{0}}{\gamma_{0}} \mathrm{H}_{\mathrm{A}},
$$

where $\mathrm{g}$ is the gravity measured at the surface of the Earth, $\gamma_{0}$ is the normal gravity of the ellipsoidal corresponding to the $45^{\circ}$ of Northern Latitude, $\mathrm{H}_{\mathrm{A}}$ is orthometric height of the datum $\mathrm{A}, \mathrm{H}_{\mathrm{B}}$ is orthometric height of the datum $\mathrm{B}$, and $\overline{\mathrm{g}}_{\mathrm{A}}$ and $\overline{\mathrm{g}}_{\mathrm{B}}$ are the mean gravities of the datum $\mathrm{A}$ and $\mathrm{B}$ at the surface of the Earth to the corresponding geoid along the plumb lines, respectively. In practice, Eq. (3) is discreted to 


$$
\Delta \mathrm{N}_{\mathrm{AB}}=\sum_{\mathrm{i}=1}^{\mathrm{n}} \Delta \mathrm{N}_{\mathrm{i}}=-\sum_{\mathrm{i}=1}^{\mathrm{n}} \theta_{\mathrm{i}} s_{\mathrm{i}}-\sum_{\mathrm{i}=1}^{\mathrm{n}} \frac{\mathrm{g}_{\mathrm{i}}-\gamma_{0}}{\gamma_{0}} \Delta \mathrm{H}_{\mathrm{i}}+\frac{\overline{\mathrm{g}}_{\mathrm{B}}-\gamma_{0}}{\gamma_{0}} \mathrm{H}_{\mathrm{B}}-\frac{\overline{\mathrm{g}}_{A}-\gamma_{0}}{\gamma_{0}} \mathrm{H}_{\mathrm{A}},
$$

in which $\mathrm{n}$ stand for partition number along ship route, $\theta_{\mathrm{i}}, \mathrm{s}_{\mathrm{i}}$ and $\mathrm{g}_{\mathrm{i}}$ are the DOV, distance, and mean gravity for the $\mathrm{i}$-th segmentation respectively. $\Delta \mathrm{N}_{\mathrm{i}}$ is the geoid undulation difference between the $\mathrm{i}$-th station and the (i-1)-th station. $\Delta \mathrm{H}_{\mathrm{i}}$ is the difference of orthometric height between the $\mathrm{i}$-th station and the (i-1)-th station. As shown in Fig. 1, $\Delta \mathrm{H}_{\mathrm{i}}$ is estimated according to the relationship of orthometric height $\mathrm{H}$, ellipsoidal height $\mathrm{h}$, and geoid height $\mathrm{N}$ as

$$
\Delta \mathrm{H}_{\mathrm{i}}=\left(\mathrm{h}_{\mathrm{i}}-\mathrm{N}_{\mathrm{i}}\right)-\left(\mathrm{h}_{\mathrm{i}-1}-\mathrm{N}_{\mathrm{i}-1}\right)=\Delta \mathrm{h}_{\mathrm{i}}-\Delta \mathrm{N}_{\mathrm{i}} \quad(\mathrm{i}=2,3, \ldots, \mathrm{n}),
$$

where $\Delta \mathrm{h}_{\mathrm{i}}$ is the difference of ellipsoidal height derived from the GNSS measurements for the i-th segmentation. The distance of the i-th segmentation consists of many small segmentations $\left(\Delta \mathrm{s}_{\mathrm{i}^{\prime}}\right)$, and $\Delta \mathrm{h}_{\mathrm{i}}$ consists of many small ellipsoidal height differences, i.e. $\Delta \mathrm{h}_{\mathrm{i}}=\sum_{\mathrm{i}^{\prime}=1}^{\mathrm{p}} \Delta \mathrm{h}_{\mathrm{i}^{\prime}}\left(\mathrm{p}=\mathrm{s}_{\mathrm{i}} / \Delta \mathrm{s}_{\mathrm{i}^{\prime}}\right)$. Substituting Eq. (5) into Eq. (4), we can get

$$
\Delta \mathrm{N}_{\mathrm{AB}}=-\sum_{\mathrm{i}=1}^{\mathrm{n}}\left(\theta_{\mathrm{i}} \mathrm{s}_{\mathrm{i}}+\frac{\mathrm{g}_{\mathrm{i}}-\gamma_{0}}{\gamma_{0}} \Delta \mathrm{h}_{\mathrm{i}}-\left(\frac{\overline{\mathrm{g}}_{\mathrm{B}}-\gamma_{0}}{\gamma_{0}} \mathrm{H}_{\mathrm{B}}-\frac{\overline{\mathrm{g}}_{A}-\gamma_{0}}{\gamma_{0}} \mathrm{H}_{\mathrm{A}}\right) / \mathrm{n}\right)\left(1-\frac{\mathrm{g}_{\mathrm{i}}-\gamma_{0}}{\gamma_{0}}\right)^{-1},
$$

So the orthometric height difference between datum A and B is

$$
\begin{aligned}
\Delta \mathrm{H}_{\mathrm{AB}}= & \mathrm{H}_{\mathrm{B}}-\mathrm{H}_{\mathrm{A}}=\left(\mathrm{h}_{\mathrm{B}}-\mathrm{N}_{\mathrm{B}}\right)-\left(\mathrm{h}_{\mathrm{A}}-\mathrm{N}_{\mathrm{A}}\right)=\Delta \mathrm{h}_{\mathrm{AB}}-\Delta \mathrm{N}_{\mathrm{AB}} \\
= & \Delta \mathrm{h}_{\mathrm{AB}} \\
& +\sum_{\mathrm{i}=1}^{\mathrm{n}}\left(\theta_{\mathrm{i}} \mathrm{s}_{\mathrm{i}}+\frac{\mathrm{g}_{\mathrm{i}}-\gamma_{0}}{\gamma_{0}} \Delta \mathrm{h}_{\mathrm{i}}-\left(\frac{\overline{\mathrm{g}}_{\mathrm{B}}-\gamma_{0}}{\gamma_{0}} \mathrm{H}_{\mathrm{B}}-\frac{\overline{\mathrm{g}}_{A}-\gamma_{0}}{\gamma_{0}} \mathrm{H}_{\mathrm{A}}\right) / \mathrm{n}\right)\left(1-\frac{\mathrm{g}_{\mathrm{i}}-\gamma_{0}}{\gamma_{0}}\right)^{-1} .
\end{aligned}
$$

The gravity values measured on datum $A$ and $B$ denote $g_{A}$ and $g_{B}$, respectively. Because $\mathrm{A}$ and B are located near the coasts (Fig. 1), their orthometric heights are very small. Therefore, when Eq. (4) is used in the orthometric height connection across sea, it is safe to assume that $\overline{\mathrm{g}}_{\mathrm{A}} \approx \mathrm{g}_{\mathrm{A}}$ and $\overline{\mathrm{g}}_{\mathrm{B}} \approx \mathrm{g}_{\mathrm{B}}$. The equation $\Delta \mathrm{h}_{\mathrm{AB}}=\mathrm{h}_{\mathrm{B}}-\mathrm{h}_{\mathrm{A}}=\sum_{\mathrm{i}=1}^{\mathrm{n}} \mathrm{h}_{\mathrm{i}}$ is theoretically a check condition. Then the orthometric height equation of $\mathrm{H}_{B}$ is

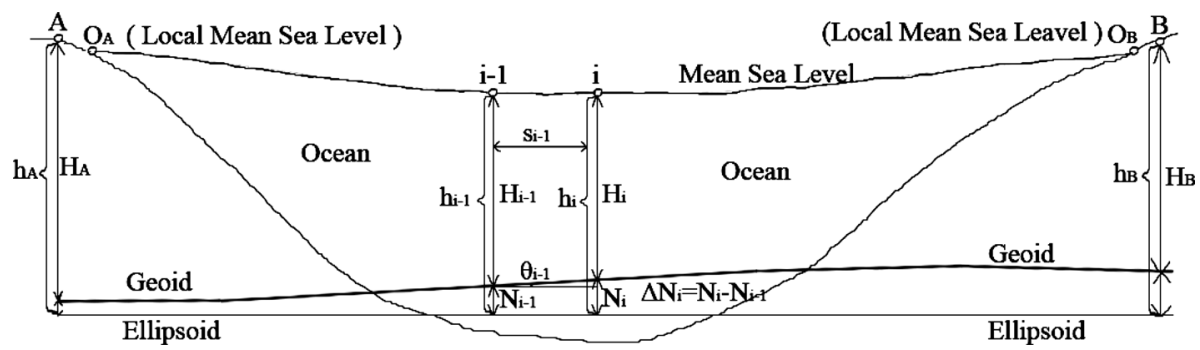

Fig. 1 The orthometric height connection across sea 


$$
\begin{aligned}
\mathrm{H}_{\mathrm{B}}= & \frac{\mathrm{H}_{\mathrm{A}}+\Delta \mathrm{h}_{\mathrm{AB}}+\sum_{\mathrm{i}=1}^{\mathrm{n}}\left(\theta_{\mathrm{i}} \mathrm{s}_{\mathrm{i}}+\frac{\mathrm{g}_{\mathrm{i}}-\gamma_{0}}{\gamma_{0}} \Delta \mathrm{h}_{\mathrm{i}}+\frac{\frac{\mathrm{g}_{\mathrm{A}}-\gamma_{0}}{\gamma_{0}} \mathrm{H}_{\mathrm{A}}}{\mathrm{n}}\right)\left(1-\frac{\mathrm{g}_{\mathrm{i}}-\gamma_{0}}{\gamma_{0}}\right)^{-1}}{\sum_{\mathrm{i}=1}^{\mathrm{n}} \frac{1}{\mathrm{n}}\left(1+\frac{\mathrm{g}_{\mathrm{B}}-\gamma_{0}}{\gamma_{0}}\left(1-\frac{\mathrm{g}_{\mathrm{i}}-\gamma_{0}}{\gamma_{0}}\right)^{-1}\right)} \\
= & \frac{\mathrm{H}_{\mathrm{A}}+\sum_{\mathrm{i}=1}^{\mathrm{n}}\left(\theta_{\mathrm{i}} \mathrm{s}_{\mathrm{i}}+\Delta \mathrm{h}_{\mathrm{i}}+\frac{\mathrm{g}_{\mathrm{A}}-\gamma_{0}}{\gamma_{0}} \frac{\mathrm{H}_{\mathrm{A}}}{\mathrm{n}}\right)\left(1-\frac{\mathrm{g}_{\mathrm{i}}-\gamma_{0}}{\gamma_{0}}\right)^{-1}}{1+\sum_{\mathrm{i}=1}^{\mathrm{n}} \frac{\frac{\mathrm{g}_{\mathrm{B}}-\gamma_{0}}{\gamma_{0}}\left(1-\frac{\mathrm{g}_{\mathrm{i}}-\gamma_{0}}{\gamma_{0}}\right)^{-1}}{\mathrm{n}}} .
\end{aligned}
$$

\subsection{Accuracy analysis}

In order to connect the height datum across sea, it is necessary to determine the gravity anomalies, DOVs, ellipsoidal heights, and the segment length along the ship route in Eq. (8). The height connection route is divided into $\mathrm{n}$ segments in the summation of Eq. (8). Based on the error propagation theory and the assumption that the measurements of all segments are independent, the error of $\mathrm{H}_{B}$ can be written as

$$
\begin{aligned}
\mathrm{m}_{\mathrm{H}_{\mathrm{B}}}^{2}= & \frac{\sum_{\mathrm{i}=1}^{\mathrm{n}} \mathrm{s}_{\mathrm{i}}^{2}\left(1-\frac{\mathrm{g}_{\mathrm{i}}-\gamma_{0}}{\gamma_{0}}\right)^{-2}}{\left(1+\sum_{\mathrm{i}=1}^{\mathrm{n}} \frac{\frac{\mathrm{g}_{\mathrm{B}}-\gamma_{0}}{\gamma_{0}}\left(1-\frac{\mathrm{g}_{\mathrm{i}}-\gamma_{0}}{\gamma_{0}}\right)^{-1}}{\mathrm{n}}\right)^{2}} \mathrm{~m}_{\theta_{\mathrm{i}}}^{2}+\frac{\sum_{\mathrm{i}=1}^{\mathrm{n}}\left(1-\frac{\mathrm{g}_{\mathrm{i}}-\gamma_{0}}{\gamma_{0}}\right)^{-2}}{\left(1+\sum_{\mathrm{i}=1}^{\mathrm{n}} \frac{\frac{\mathrm{g}_{\mathrm{B}}-\gamma_{0}}{\gamma_{0}}\left(1-\frac{\mathrm{g}_{\mathrm{i}}-\gamma_{0}}{\gamma_{0}}\right)^{-1}}{\mathrm{n}}\right)^{2}} \mathrm{~m}_{\Delta \mathrm{h}_{\mathrm{i}}}^{2} \\
& +\frac{\sum_{\mathrm{i}=1}^{\mathrm{n}} \theta_{\mathrm{i}}^{2}\left(1-\frac{\mathrm{g}_{\mathrm{i}}-\gamma_{0}}{\gamma_{0}}\right)^{-2}}{\left(1+\sum_{\mathrm{i}=1}^{\mathrm{n}} \frac{\frac{\mathrm{g}_{\mathrm{B}}-\gamma_{0}}{\gamma_{0}}\left(1-\frac{\mathrm{g}_{\mathrm{i}}-\gamma_{0}}{\gamma_{0}}\right)^{-1}}{\mathrm{n}}\right)^{2} \mathrm{~m}_{\mathrm{s}_{\mathrm{i}}}^{2}} \\
& +\frac{\left(\sum_{\mathrm{i}=1}^{\mathrm{n}}\left(\theta_{i} \mathrm{~s}_{\mathrm{i}}+\Delta \mathrm{h}_{\mathrm{i}}+\frac{\mathrm{H}_{\mathrm{A}}}{\mathrm{n}}\left(\frac{\mathrm{g}_{\mathrm{A}}-\gamma_{0}}{\gamma_{0}}-\frac{\mathrm{g}_{\mathrm{B}}-\gamma_{0}}{\gamma_{0}}\right)\right) \frac{1}{\gamma_{0}}\left(1-\frac{\mathrm{g}_{\mathrm{i}}-\gamma_{0}}{\gamma_{0}}\right)^{-2}\right)^{2}}{\left(1+\sum_{\mathrm{i}=1}^{\mathrm{n}} \frac{\frac{\mathrm{g}_{\mathrm{B}}-\gamma_{0}}{\gamma_{0}}\left(1-\frac{\mathrm{g}_{\mathrm{i}}-\gamma_{0}}{\gamma_{0}}\right)^{-1}}{\mathrm{n}}\right)_{\mathrm{g}_{\mathrm{i}}}^{2}},
\end{aligned}
$$

where $\mathrm{m}_{\mathrm{H}_{\mathrm{B}}}, \mathrm{m}_{\theta_{\mathrm{i}}}, \mathrm{m}_{\triangle \mathrm{h}_{\mathrm{i}}}, \mathrm{m}_{\mathrm{s}_{\mathrm{i}}}$ and $\mathrm{m}_{\mathrm{g}_{\mathrm{i}}}$ represent the orthometric height error of $\mathrm{B}$, the error of DOV component along $\mathrm{AB}$, ellipsoidal height difference error, distance error and the mean gravity anomaly error for the i-th segmentation, respectively.

When the ship is travelling at the sea surface, gravities and ellipsoid coordinates are measured by gravimeter and GNSS receiver at the same time. The ellipsoidal heights $\mathrm{H}_{\mathrm{ai}}$ of ship-borne GNSS antenna for the i-th segmentation can be precisely determined with the kinematic positioning method under the condition of approximately constant ship speed and stable sea state by the ship-borne GNSS receiver and antenna (Guo et al. 2014). The draft depth becomes lower due to the oil consumption. Therefore, to determine the sea surface heights (SSHs) precisely along the route, it is necessary to continuously record the distances between the GNSS antenna and the sea surface for each epoch. The $\mathrm{SSH} \mathrm{H}_{\mathrm{i}}$ is estimated according to the relationship between the distance $\mathrm{H}_{\mathrm{ai}}$ and the distance Has $\mathrm{H}_{\mathrm{i}}$, which is the vertical distance from the GNSS antenna to the sea surface for the i-th segmentation 


$$
\mathrm{H}_{\mathrm{i}}=\mathrm{H}_{\mathrm{ai}}-\mathrm{Has}_{\mathrm{i}} \text {. }
$$

The ship-borne gravity is affected by various factors, such as temperature, air pressure and Heutte Wisch effect which are caused by the moving ship. To reduce these effects, the ship-borne gravimeter is usually fixed in one gyro system. The gravity anomalies can be precisely measured with a resolution of $1-2 \mathrm{~km}$. To reduce the space reduction errors, the distances between the gravimeter and the sea surface must be precisely measured. One pose meter is fixed on the ship to measure the roll, yaw and pitch. To reduce the noises caused by wind and wave, the Gauss filter is used to filter the gravity data. The collinear adjustment method is also used to improve the accuracy of the gravity measurements (Guo et al. 2014).

The errors in ship-borne gravimetry and GNSS measurements along the ship route are inevitable for orthometric height connection across sea. The effect of DOV error, ellipsoidal height difference error, measured gravity error, and distance error of each segmentation on the precision of orthometric height connection across sea respectively is researched according to Eq. (9). In general, DOVs do not exceed $20^{\prime \prime}$ on the sea surface, the ellipsoidal height differences are less than $5 \mathrm{~m}$, the gravity anomalies are less than $200 \mathrm{mGal}$, and the normal gravity is about $980 \mathrm{Gal}$ (Guan and Ning 1981; Guo et al. 2013, 2014). So the research is conducted under $\gamma=980 \mathrm{Gal}, \mathrm{g}_{\mathrm{A}}-\gamma_{0 A}=\mathrm{g}_{\mathrm{B}}-\gamma_{O B}=\mathrm{g}-\gamma$ $=200 \mathrm{mGal}, \theta=20^{\prime \prime}, \Delta \mathrm{h}=5 \mathrm{~m}$. The connection distance across sea is assumed to be $100 \mathrm{~km}$. The length for each segmentation is changed from $1 \mathrm{~km}$ to $100 \mathrm{~km}$ with a $1 \mathrm{~km}$ step. Because the DOVs along the ship route are very small on the sea surface, the precision of DOV is set from $0.1^{\prime \prime}$ to $2.0^{\prime \prime}$ with a $0.1^{\prime \prime}$ increment for each segmentation. One double-frequency GNSS receiver is used to acquire GNSS data, and post processing is made to estimate precisely the GNSS antenna height. Then the height is reduced to the sea surface. To further improve the accuracy of the orthometric height connection, the Gauss filter is used to filter the difference between the GNSS SSHs and the averaged sea surface height model such as DTU10MSS (Andersen 2010) thus the noises which are caused by wind and wave are filtered. Collinear adjustment can further improve the accuracy of SSHs by $5 \mathrm{~cm}$, and the accuracy of the ellipsoidal height difference is better than $3.5 \mathrm{~cm}$ (Guo et al. 2014). The precision of ellipsoidal height difference is set from 10 to $30 \mathrm{~mm}$ with $1 \mathrm{~mm}$ increment for each segmentation along the ship route. The root mean squared error of ship borne gravity is about $3 \mathrm{mGal}$ by analysis of crossover coincident value (Huang et al. 2005). To reduce the gravimetric errors caused by the ship locations, the post processing of ship borne double frequency GNSS data is made to precisely estimate the ship positions, which can make the gravimetric errors better than $0.5 \mathrm{mGal}$ (Guo et al. 2014). The precision of the measured gravity errors is set from $10 \mathrm{mGal}$ to $30 \mathrm{mGal}$ with a $1 \mathrm{mGal}$ step for each segmentation along the ship route. Because the DOV is very small on the sea surface ship route, the effect of each segment distance errors for the orthometric height connection is very limited. For example, when the deflection of the vertical is $20^{\prime \prime}$ and the accumulated distance error is $20 \mathrm{~m}$, the orthometric height connection error is $1.8 \mathrm{~mm}$. The precision of distance along the ship route is set from 0.10 to $1.00 \mathrm{~m}$ with a $0.10 \mathrm{~m}$ step along the ship route for each segmentation. When calculating the effect of one error on the precision of orthometric height connection across sea, the other three errors are set to be a constant, e.g. $\mathrm{m}_{\theta}=1.0^{\prime \prime}, m_{\Delta h}=10 \mathrm{~mm}, \mathrm{~m}_{\mathrm{s}}=0.2 \mathrm{~m}$ and $\mathrm{m}_{\mathrm{g}}=10 \mathrm{mGal}$. The result is shown in Fig. 2.

Figure 2a shows the effect of DOV errors on the determination of orthometric height connection across sea. Obviously, the orthometric height connection precision is decreased with the DOV errors becoming large. However, the changed amplitude of DOV errors on 
(a)

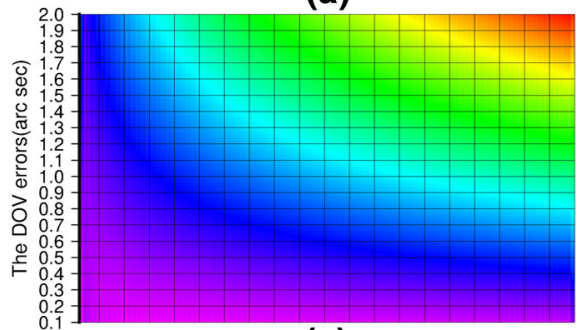

(c)

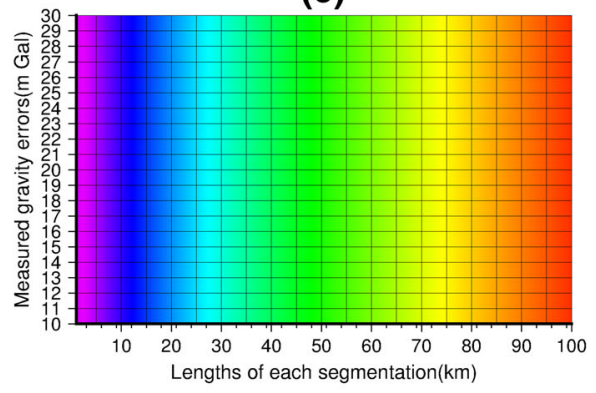

(b)

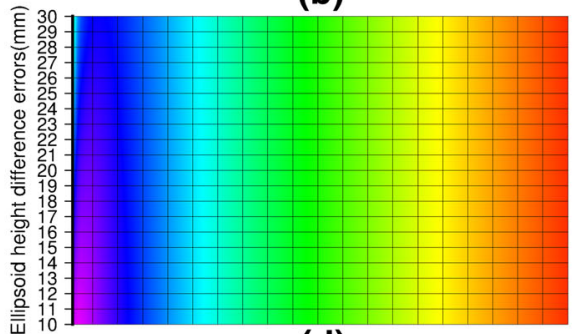

(d)

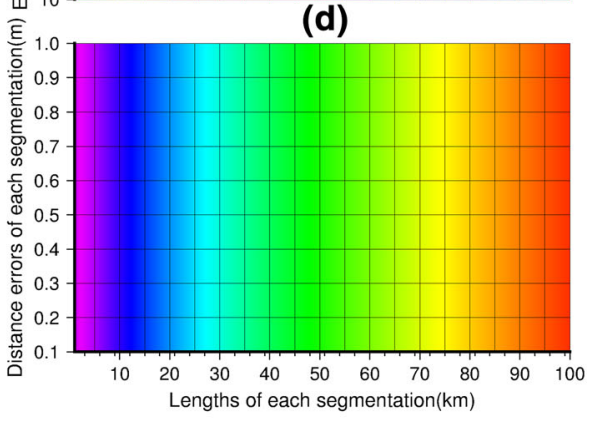

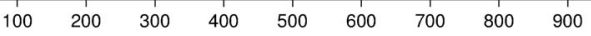

Fig. 2 The effect of DOV error ((a) with $\mathrm{m}_{\Delta \mathrm{h}} 10 \mathrm{~mm}, \mathrm{~m}_{\mathrm{s}} 0.2 \mathrm{~m}$ and $\left.\mathrm{m}_{\mathrm{g}} 10 \mathrm{mGal}\right)$, ellipsoidal height difference error $\left((\mathbf{b})\right.$ with $\mathrm{m}_{\theta} 1.0^{\prime \prime}, \mathrm{m}_{\mathrm{s}} 0.2 \mathrm{~m}$ and $\left.\mathrm{m}_{\mathrm{g}} 10 \mathrm{mGal}\right)$, measured gravity error $\left((\mathbf{c})\right.$ with $\mathrm{m}_{\theta} 1.0^{\prime \prime}$, $\mathrm{m}_{\Delta \mathrm{h}} 10 \mathrm{~mm}$ and $\left.\mathrm{m}_{\mathrm{s}} 0.2 \mathrm{~m}\right)$, and distance error $\left((\mathbf{d}) \mathrm{m}_{\theta} 1.0^{\prime \prime}, \mathrm{m}_{\Delta \mathrm{h}} 10 \mathrm{~mm}\right.$ and $\left.\mathrm{m}_{\mathrm{g}} 10 \mathrm{mGal}\right)$ of each segment on the precision of orthometric height connection across sea

orthometric height connection precision is varied with respective to the length of each segmentation. The basic regularity of the changed amplitude is that the changed amplitude gradually becomes big with each segment length becoming long. For example, the precision of DOV for each segment of $2.0 \mathrm{~km}$ is changed from $2.0^{\prime \prime}$ to $0.1^{\prime \prime}$, the orthometric height connection precision is improved from 154.30 to $71.09 \mathrm{~mm}$ whose improving rate is 1.17. While the precision of DOV for each segment of $50 \mathrm{~km}$ is changed from $2.0^{\prime \prime}$ to $0.1^{\prime \prime}$, the precision of orthometric height connection precision is improved from 685.76 to $37.08 \mathrm{~mm}$ whose improving rate is 17.49 . Figure $2 \mathrm{~b}$ shows the effect of ellipsoidal height difference errors on the precision of orthometric height connection across sea. The orthometric height connection precision is deduced with the ellipsoidal height difference errors becoming large. And also the changed amplitude of the ellipsoidal height difference errors for the orthometric height connection precision is varied with different lengths of each segmentation. But to the contrary of the DOV errors, the effect of ellipsoidal height difference errors for the changed amplitude is gradually becoming small with the distance of each segmentation becoming long. For example, the precision of ellipsoidal height difference for each segment of $2.0 \mathrm{~km}$ is changed from 30 to $10 \mathrm{~mm}$, the orthometric height connection precision is improved from 222.95 to $98.53 \mathrm{~mm}$ whose improving rate is 1.26. While the precision of ellipsoidal height difference for each segment of $50 \mathrm{~km}$ is changed from 30 to $10 \mathrm{~mm}$, the precision of orthometric height connection is improved from 345.42 to $343.1 \mathrm{~mm}$ whose improving rate is 0.01 . Figure $2 \mathrm{c}$ shows that, the effect of gravimetric errors on the orthometric height connection first becomes small then becomes large with the length of each segmentation becoming short. Fixing the length of each 
segmentation a constant, the orthometric height connection errors are almost unchanged with respective to the gravimetric errors. Keeping the length of each segmentation a constant, the maximum varied value of orthometric height connection error is less than $1 \mathrm{~mm}$ with the gravimetric error changing from 10 to $30 \mathrm{mGal}$. Figure $2 \mathrm{~d}$ shows that, the effect of each segment distance errors on the orthometric height connection first become small then become large with each segmentation length becoming short. Keeping the length of each segmentation a constant, the orthometric height connection errors are almost unchanged with respective to each segment distance errors. When the segmentation length is equal, the orthometric height connection errors in Fig. $2 \mathrm{c}, \mathrm{d}$ almost look the same. It means that the effect of gravimetric errors and each segment distance errors on the orthometric height connection precision is very small, and is far less than the effect of each segmentation length on the orthometric height connection precision. The effect of each segmentation length on the orthometric height connection errors first becomes small then becomes large with the length of each segmentation becoming short.

The above analysis shows that only choosing the optimal length of segmentation according to the estimated DOV errors and ellipsoidal height difference errors, we can get the best results for orthometric height connection across sea.

\subsection{Optimal partition number}

According to Sect. 2.2, the choice of the optimal partition number plays an important role in achieving the high precision orthometric height connection across sea. The effect of gravimetric error and segment distance error on the orthometric height connection precision across sea is very small according to Eq. (9). The effects of the DOV error of each segmentation and the ellipsoidal height difference error are the main factors on the orthometric height connection precision according to the analysis of Sect. 2.2. Therefore, the Eq. (9) can be simplified as

$$
\mathrm{m}_{\mathrm{H}_{\mathrm{B}}}^{2} \approx \frac{\sum_{\mathrm{i}=1}^{\mathrm{n}} \mathrm{s}_{\mathrm{i}}^{2}\left(1-\frac{\mathrm{g}_{\mathrm{i}}-\gamma_{0 \mathrm{i}}}{\gamma_{0 \mathrm{i}}}\right)^{-2}}{\left(1+\sum_{\mathrm{i}=1}^{n} \frac{\frac{\mathrm{g}_{\mathrm{B}}-\gamma_{0 \mathrm{~B}}}{\gamma_{0 \mathrm{~B}}}\left(1-\frac{\mathrm{g}_{\mathrm{i}}-\gamma_{0 \mathrm{i}}}{\gamma_{0 i}}\right)^{-1}}{\mathrm{n}}\right)^{2}} \mathrm{~m}_{\theta_{\mathrm{i}}}^{2} \frac{\sum_{\mathrm{i}=1}^{\mathrm{n}}\left(1-\frac{\mathrm{g}_{\mathrm{i}}-\gamma_{0 \mathrm{i}}}{\gamma_{0 \mathrm{i}}}\right)^{-2}}{\left(1+\sum_{\mathrm{i}=1}^{\mathrm{n}} \frac{\frac{\mathrm{g}_{\mathrm{B}}-\gamma_{0 \mathrm{~B}}}{\gamma_{0 \mathrm{~B}}}\left(1-\frac{\mathrm{g}_{\mathrm{i}}-\gamma_{0 \mathrm{i}}}{\gamma_{0 \mathrm{i}}}\right)^{-1}}{\mathrm{n}}\right)^{2}} \mathrm{~m}_{\Delta \mathrm{h}_{\mathrm{i}}}^{2}
$$

Assuming the lengths of each segmentation $s_{i}$ are the same, the relationship between the total distance 1 and partition number $\mathrm{n}$ is $\mathrm{s}=1 / \mathrm{n}$. Solving Eq. (11), $\mathrm{n}$ can be written as

$\mathrm{n}=\frac{\left(1+\frac{\mathrm{g}_{\mathrm{B}}-\gamma_{0 \mathrm{~B}}}{\gamma_{0 B}}\left(1-\frac{\mathrm{g}-\gamma_{0}}{\gamma_{0}}\right)^{-1}\right)^{2} \mathrm{~m}_{\mathrm{H}_{\mathrm{B}}}^{2}+\sqrt{\left(1+\frac{\mathrm{g}-\gamma_{0 B}}{\gamma_{0 B}}\left(1-\frac{\mathrm{g}-\gamma_{0}}{\gamma_{0}}\right)^{-1}\right)^{4} \mathrm{~m}_{\mathrm{H}_{\mathrm{B}}}^{4}-4 m_{\Delta h}^{2}\left(1-\frac{\mathrm{g}-\gamma_{0}}{\gamma_{0}}\right)^{-2} 1^{2} \mathrm{~m}_{\theta}^{2}\left(1-\frac{\mathrm{g}-\gamma_{0}}{\gamma_{0}}\right)^{-2}}}{2 \mathrm{~m}_{\Delta \mathrm{h}}^{2}\left(1-\frac{\mathrm{g}-\gamma_{0}}{\gamma_{0}}\right)^{-2}}$.

In general, the gravity anomalies are $<200 \mathrm{mGal}$ and the normal gravities are about $980 \mathrm{Gal}$. Under the assumption that $\mathrm{g}-\gamma_{0}=\mathrm{g}_{\mathrm{B}}-\gamma_{0 \mathrm{~B}}=200 \mathrm{mGal}$ and $\gamma_{0}=\gamma_{0 \mathrm{~B}}=980000 \mathrm{mGal}$, Eq. (12a) becomes

$$
\mathrm{n}=\left(\mathrm{m}_{\mathrm{H}_{\mathrm{B}}}^{2}+\sqrt{\mathrm{m}_{\mathrm{H}_{\mathrm{B}}}^{4}-4 \mathrm{~m}_{\Delta \mathrm{h}}^{2} 1^{2} \mathrm{~m}_{\theta}^{2}}\right) /\left(2 \mathrm{~m}_{\Delta \mathrm{h}}^{2}\right) .
$$


Table 1 Relationship between the partition number and the precision of orthometric height connection
Symbol "-" means that the results $4 m_{\Delta \mathrm{h}}^{2} 1^{2} \mathrm{~m}_{\theta}^{2}$ are bigger than the results $\mathrm{m}_{\mathrm{H}_{\mathrm{B}}}^{4}$, so it exceeds the range of calculation

\begin{tabular}{|c|c|c|c|c|c|c|}
\hline \multirow[t]{2}{*}{$\mathrm{m}_{\Delta \mathrm{h}}(\mathrm{mm})$} & \multirow[t]{2}{*}{$\mathrm{m}_{\mathrm{H}_{\mathrm{B}}}(\mathrm{m})$} & \multicolumn{5}{|c|}{$\mathrm{m}_{\theta}(\operatorname{arc}$ second $)$} \\
\hline & & $0.1^{\prime \prime}$ & $0.3^{\prime \prime}$ & $0.5^{\prime \prime}$ & $1.0^{\prime \prime}$ & $1.5^{\prime \prime}$ \\
\hline \multirow[t]{6}{*}{10} & 0.20 & 390 & 340 & - & - & - \\
\hline & 0.25 & 620 & 590 & 510 & - & - \\
\hline & 0.30 & 900 & 880 & 830 & - & - \\
\hline & 0.35 & 1220 & 1210 & 1170 & 990 & - \\
\hline & 0.40 & 1600 & 1590 & 1560 & 1440 & 1130 \\
\hline & 0.45 & 2020 & 2010 & 2000 & 1900 & 1720 \\
\hline \multirow[t]{7}{*}{15} & 0.20 & 170 & - & - & - & - \\
\hline & 0.25 & 280 & 240 & - & - & - \\
\hline & 0.30 & 400 & 380 & 320 & - & - \\
\hline & 0.35 & 540 & 530 & 490 & - & - \\
\hline & 0.40 & 710 & 700 & 680 & 500 & - \\
\hline & 0.45 & 900 & 890 & 870 & 770 & - \\
\hline & 0.50 & 1110 & 1100 & 1090 & 1010 & 830 \\
\hline \multirow[t]{7}{*}{20} & 0.25 & 150 & 110 & - & - & - \\
\hline & 0.30 & 220 & 200 & - & - & - \\
\hline & 0.35 & 300 & 290 & 250 & - & - \\
\hline & 0.40 & 400 & 390 & 360 & - & - \\
\hline & 0.45 & 500 & 500 & 470 & 330 & - \\
\hline & 0.50 & 620 & 620 & 600 & 510 & - \\
\hline & 0.55 & 760 & 750 & 740 & 670 & 480 \\
\hline \multirow[t]{7}{*}{25} & 0.30 & 140 & 110 & - & - & - \\
\hline & 0.35 & 190 & 180 & 110 & - & - \\
\hline & 0.40 & 260 & 240 & 210 & - & - \\
\hline & 0.45 & 320 & 310 & 290 & - & - \\
\hline & 0.50 & 400 & 390 & 380 & 250 & - \\
\hline & 0.55 & 480 & 480 & 460 & 390 & - \\
\hline & 0.60 & 580 & 570 & 600 & 500 & - \\
\hline \multirow[t]{5}{*}{30} & 0.40 & 180 & 160 & 130 & - & - \\
\hline & 0.45 & 220 & 210 & 190 & - & - \\
\hline & 0.50 & 280 & 270 & 250 & - & - \\
\hline & 0.55 & 340 & 330 & 320 & 210 & - \\
\hline & 0.60 & 400 & 390 & 380 & 320 & - \\
\hline
\end{tabular}

If the total distance 1 is assumed to be $1000 \mathrm{~km}$, the relationship between the partition number and orthometric height connection errors is shown in Table 1.

From Table 1, the optimal partition number ranges from 110 to 510 provide that the accuracy of ellipsoidal height difference for GNSS measurement is better than $3.0 \mathrm{~cm}$ and the accuracy of the DOV for each segmentation is better than $1.0^{\prime \prime}$. So, the partition numbers $100,200,400$ and 500 are chosen in practical case calculation, which means the length of each segment is $10,5,2.5$ and $2.0 \mathrm{~km}$, respectively. 


\section{Calculation of DOVs along the ship route}

To calculate the orthometric height of B, one needs the value of DOVs, ellipsoidal heights and gravity values for each segmentation along the ship route and the orthometric height of A according to Eq. (8). The ellipsoidal height and gravity can be obtained directly from ship-borne GNSS measurements and gravimetric data. The DOVs, on the other hand, cannot be determined using the mentioned techniques. As discussed in Sect. 2, the DOV error has large impact on the orthometric height connection. Unfortunately, it is difficult to measure DOV accurately on the route of the ship. However, it is possible to measure the gravities accurately. The DOVs along the ship route can then be computed according to the relationship between DOV and gravity. To improve the accuracy of DOVs along the ship route, the remove-restore technique (Rapp and Rummel 1975) is used to compute the DOVs. The long wave length part of earth gravity model $\Delta \mathrm{g}_{\mathrm{i}}^{\mathrm{GM}}$ is removed from the measured gravity anomaly $\Delta \mathrm{g}_{\mathrm{i}}$. The remaining residual gravity anomaly $\Delta \mathrm{g}_{\mathrm{i}}^{\text {res }}$, which is related to the residual DOV components $\xi_{i}^{\text {res }}$ and $\eta_{i}^{\text {res }}$, is computed for the $i$-th segment. The residual DOV components $\xi_{i}^{\text {res }}$ and $\eta_{i}^{\text {res }}$ are then added back to the model DOV components $\xi_{\mathrm{i}}^{\mathrm{GM}}$ and $\eta_{\mathrm{i}}^{\mathrm{GM}}$ to restore the DOV components $\xi_{\mathrm{i}}$ and $\eta_{\mathrm{i}}$ of the i-th segment. Model gravity anomalies and model DOVs can be calculated by a precise earth gravity field model such as EGM2008 (up to degree 2190) (Pavlis et al. 2012). The residual DOV components $\xi_{i}^{\text {res }}$ and $\eta_{i}^{\text {res }}$ can be estimated from the residual gravity anomaly $\Delta \mathrm{g}_{\mathrm{i}}^{\text {res }}$ for the i-th segment using the LSC method (Heiskanen and Moritz 1967). The LSC is especially suitable for the calculation of the regional high frequency data, which may have limited amount of data. The formula is

$$
\mathrm{X}=\mathrm{C}_{\mathrm{XL}}\left(\mathrm{C}_{\mathrm{LL}}+\mathrm{D}\right)^{-1} \mathrm{~L},
$$

where $\mathrm{X}$ is the signal vector to be estimated. $\mathrm{L}$ is the observation vector. $\mathrm{C}_{\mathrm{XL}}$ represents the cross-covariance function between the observations and signals. $\mathrm{C}_{\mathrm{LL}}$ denotes the covariance function of observations. D is the noise matrix. Substituting the measured gravities, the covariance function of gravity anomalies and the cross-covariance function between gravity anomalies and DOV components into Eq. (13) and assuming the noise matrix D is zero, the formula of residual DOVs components can be written as,

$$
\left\{\begin{array}{c}
{\left[\begin{array}{c}
\xi_{1}^{\text {res }} \\
\cdots \\
\xi_{\mathrm{k}}^{\text {res }}
\end{array}\right]=\left[\begin{array}{ccc}
\operatorname{cov}\left(\xi_{1}, \Delta \mathrm{g}_{1}\right) & \cdots & \operatorname{cov}\left(\xi_{1}, \Delta \mathrm{g}_{\mathrm{j}}\right) \\
\cdots & \cdots & \cdots \\
\operatorname{cov}\left(\xi_{\mathrm{k}}, \Delta \mathrm{g}_{1}\right) & \cdots & \operatorname{cov}\left(\xi_{\mathrm{k}}, \Delta \mathrm{g}_{\mathrm{j}}\right)
\end{array}\right]\left[\begin{array}{ccc}
\operatorname{cov}\left(\Delta \mathrm{g}_{1}, \Delta \mathrm{g}_{1}\right) & \cdots & \operatorname{cov}\left(\Delta \mathrm{g}_{1}, \Delta \mathrm{g}_{\mathrm{j}}\right) \\
\cdots & \cdots & \cdots \\
\operatorname{cov}\left(\Delta \mathrm{g}_{\mathrm{j}}, \Delta \mathrm{g}_{1}\right) & \cdots & \operatorname{cov}\left(\Delta \mathrm{g}_{\mathrm{j}}, \Delta \mathrm{g}_{\mathrm{j}}\right)
\end{array}\right]^{-1}\left[\begin{array}{c}
\Delta \mathrm{g}_{1}^{\text {res }} \\
\cdots \\
\Delta \mathrm{g}_{\mathrm{j}}^{\text {res }}
\end{array}\right]} \\
{\left[\begin{array}{c}
\eta_{1}^{\text {res }} \\
\cdots \\
\eta_{\mathrm{k}}^{\text {res }}
\end{array}\right]=\left[\begin{array}{ccc}
\operatorname{cov}\left(\eta_{1}, \Delta \mathrm{g}_{1}\right) & \cdots & \operatorname{cov}\left(\eta_{1}, \Delta \mathrm{g}_{\mathrm{j}}\right) \\
\cdots & \cdots & \cdots \\
\operatorname{cov}\left(\eta_{\mathrm{k}}, \Delta \mathrm{g}_{1}\right) & \cdots & \operatorname{cov}\left(\eta_{\mathrm{k}}, \Delta \mathrm{g}_{\mathrm{j}}\right)
\end{array}\right]\left[\begin{array}{ccc}
\operatorname{cov}\left(\Delta \mathrm{g}_{1}, \Delta \mathrm{g}_{1}\right) & \cdots & \operatorname{cov}\left(\Delta \mathrm{g}_{1}, \Delta \mathrm{g}_{\mathrm{j}}\right) \\
\cdots & \cdots & \cdots \\
\operatorname{cov}\left(\Delta \mathrm{g}_{\mathrm{j}}, \Delta \mathrm{g}_{1}\right) & \cdots & \operatorname{cov}\left(\Delta \mathrm{g}_{\mathrm{j}}, \Delta \mathrm{g}_{\mathrm{j}}\right)
\end{array}\right]^{-1}\left[\begin{array}{c}
\Delta \mathrm{g}_{1}^{\text {res }} \\
\cdots \\
\Delta \mathrm{g}_{\mathrm{j}}^{\text {res }}
\end{array}\right]}
\end{array}\right.
$$

where $\mathrm{j}$ or $\mathrm{k}$ are the numbers of observation or signal values in a subgroup computation. The most important step in Eq. (14) is the computation of the gravity anomalies covariance function and the cross-covariance function between the gravity anomalies and the DOV components, which are conventionally computed by an empirical covariance function. Different regions have different parameters in the empirical covariance function, which restricts the application of the empirical covariance function. In this contribution, the disturbing potential spherical harmonic expansion is used to derive the covariance and 
cross-covariance function. The spherical harmonic expansion of the Earth's disturbing potential T (Rapp and Cruz 1986) is

$$
\mathrm{T}=\mathrm{W}-\mathrm{U}=\frac{\mathrm{GM}}{\mathrm{r}} \sum_{\mathrm{n}^{\prime}=2}^{\infty}\left(\frac{\mathrm{a}}{\mathrm{r}}\right)^{\mathrm{n}^{\prime}} \sum_{\mathrm{m}^{\prime}=0}^{\mathrm{n}^{\prime}}\left(\overline{\mathrm{C}}_{\mathrm{n}^{\prime} \mathrm{m}^{\prime}}^{*} \cos \mathrm{m}^{\prime} \lambda+\overline{\mathrm{S}}_{\mathrm{n}^{\prime} \mathrm{m}^{\prime}} \sin \mathrm{m}^{\prime} \lambda\right) \overline{\mathrm{P}}_{\mathrm{n}^{\prime} \mathrm{m}^{\prime}}(\cos \Theta),
$$

where $\mathrm{W}$ and $\mathrm{U}$ are gravity potential and normal gravity potential of the Earth, respectively, $r, \Theta, \lambda$ is the polar coordinate of a datum point, a is the major axis of the Earth ellipsoid n' and m' are degree and order of the spherical harmonic expansion of the Earth's disturbing potential $\mathrm{T}$, and $\overline{\mathrm{P}}_{\mathrm{n}^{\prime} \mathrm{m}^{\prime}}$ is the fully normalized Legendre function,

$$
\overline{\mathrm{C}}_{\mathrm{n}^{\prime} \mathrm{m}^{\prime}}^{*}=\left\{\begin{array}{c}
\overline{\mathrm{C}}_{\mathrm{n}^{\prime} \mathrm{m}^{\prime}}-\overline{\mathrm{C}}_{\mathrm{n}^{\prime} \mathrm{m}^{\prime}}^{\prime}, \mathrm{m}^{\prime}=0, \mathrm{n}^{\prime}=2 \mathrm{k}^{\prime}\left(\mathrm{k}^{\prime} \geq 1 \text { integer }\right), \\
\overline{\mathrm{C}}_{\mathrm{n}^{\prime} \mathrm{m}^{\prime}}, \text { others }
\end{array}\right.
$$

$\overline{\mathrm{C}}_{\mathrm{n}^{\prime} \mathrm{m}^{\prime}}$ and $\overline{\mathrm{S}}_{\mathrm{n}^{\prime} \mathrm{m}^{\prime}}$ are the fully normalized earth gravity potential coefficients, and $\overline{\mathrm{C}}_{\mathrm{n}^{\prime} \mathrm{m}^{\prime}}^{\prime}$ is the fully normalized normal ellipsoid potential coefficient, GM is the geocentric gravitational constant. According to the relationship between the DOV components, gravity anomalies and the disturbing potential, the Bruns equation and DOV components equation can be written as,

$$
\left\{\begin{array}{l}
\Delta \mathrm{g}=-\frac{\partial T}{\partial \mathrm{r}}-\frac{2}{\mathrm{r}} \mathrm{T} \\
\xi=\frac{1}{\gamma \mathrm{r}} \frac{\partial \mathrm{T}}{\partial \Theta} \\
\eta=-\frac{1}{\gamma \mathrm{r} \sin \Theta} \frac{\partial \mathrm{T}}{\partial \lambda}
\end{array} .\right.
$$

Substituting Eq. (15) into Eq. (16), we can get (Heiskanen and Moritz 1967)

$$
\left\{\begin{array}{l}
\Delta \mathrm{g}=\frac{\mathrm{GM}}{\mathrm{r}^{2}} \sum_{\mathrm{n}^{\prime}=2}^{\infty}\left(\frac{\mathrm{a}}{\mathrm{r}}\right)^{\mathrm{n}^{\prime}} \sum_{\mathrm{m}^{\prime}=0}^{\mathrm{n}^{\prime}}\left(\overline{\mathrm{C}}_{\mathrm{n}^{\prime} \mathrm{m}^{\prime}}^{*} \cos \mathrm{m}^{\prime} \lambda+\overline{\mathrm{S}}_{\mathrm{n}^{\prime} \mathrm{m}^{\prime}} \sin \mathrm{m}^{\prime} \lambda\right) \overline{\mathrm{P}}_{\mathrm{n}^{\prime} \mathrm{m}^{\prime}}(\cos \Theta) \\
\xi=\frac{1}{\gamma \mathrm{r}} \frac{\partial \mathrm{T}}{\partial \Theta}=\frac{1}{\gamma \mathrm{r}} \frac{\mathrm{GM}}{\mathrm{r}} \sum_{\mathrm{n}^{\prime}=2}^{\infty}\left(\frac{\mathrm{a}}{\mathrm{r}}\right)^{\mathrm{n}^{\prime}} \sum_{\mathrm{m}^{\prime}=0}^{\mathrm{n}^{\prime}}\left(\overline{\mathrm{C}}_{\mathrm{n}^{\prime} \mathrm{m}^{\prime}}^{*} \cos \mathrm{m}^{\prime} \lambda+\overline{\mathrm{S}}_{\mathrm{n}^{\prime} \mathrm{m}^{\prime}} \sin \mathrm{m}^{\prime} \lambda\right) \frac{\mathrm{d}\left(\overline{\mathrm{P}}_{\mathrm{n}^{\prime} \mathrm{m}^{\prime}}(\cos \Theta)\right)}{\mathrm{d} \Theta} \\
\eta=-\frac{1}{\gamma \mathrm{r} \sin \Theta} \frac{\partial \mathrm{T}}{\partial \lambda}=\frac{1}{\gamma \mathrm{r} \sin \Theta} \frac{\mathrm{GM}}{\mathrm{r}} \sum_{\mathrm{n}^{\prime}=2}^{\infty}\left(\frac{\mathrm{a}}{\mathrm{r}}\right)^{\mathrm{n}^{\prime}} \sum_{\mathrm{m}^{\prime}=0}^{\mathrm{n}^{\prime}} \mathrm{m}^{\prime}\left(\overline{\mathrm{C}}_{\mathrm{n}^{\prime} \mathrm{m}^{\prime}}^{*} \sin \mathrm{m}^{\prime} \lambda-\overline{\mathrm{S}}_{\mathrm{n}^{\prime} \mathrm{m}^{\prime}} \cos \mathrm{m}^{\prime} \lambda\right) \overline{\mathrm{P}}_{\mathrm{n}^{\prime} \mathrm{m}^{\prime}}(\cos \Theta)
\end{array} .\right.
$$

Let $\left(\frac{a}{r}\right)^{n^{\prime}} \cos m^{\prime} \lambda \bar{P}_{n^{\prime} m^{\prime}}(\cos \Theta)=A_{n^{\prime} m^{\prime}}, \quad\left(\frac{a}{r}\right)^{n^{\prime}} \sin m^{\prime} \lambda \bar{P}_{n^{\prime} m^{\prime}}(\cos \Theta)=B_{n^{\prime} m^{\prime}}, \quad\left(\frac{a}{r}\right)^{n^{\prime}} \cos m^{\prime} \lambda$ $\frac{\mathrm{d}\left(\overline{\mathrm{P}}_{\mathrm{n}^{\prime} \mathrm{m}^{\prime}}(\cos \Theta)\right)}{\mathrm{d} \Theta}=\mathrm{D}_{\mathrm{n}^{\prime} \mathrm{m}^{\prime}}, \quad\left(\frac{\mathrm{a}}{\mathrm{r}}\right)^{\mathrm{n}^{\prime}} \sin \mathrm{m}^{\prime} \lambda \frac{\mathrm{d}\left(\overline{\mathrm{P}}_{\mathrm{n}^{\prime} \mathrm{m}^{\prime}}(\cos \Theta)\right)}{d \Theta}=\mathrm{E}_{\mathrm{n}^{\prime} \mathrm{m}^{\prime}}, \quad\left(\frac{\mathrm{a}}{\mathrm{r}}\right)^{\mathrm{n}^{\prime}} \mathrm{m}^{\prime} \sin \mathrm{m}^{\prime} \lambda \frac{\overline{\mathrm{P}}_{\mathrm{n}^{\prime} \mathrm{m}^{\prime}}(\cos \Theta)}{\sin \Theta}=\mathrm{M}_{\mathrm{n}^{\prime} \mathrm{m}^{\prime}}$, and $\left(\frac{a}{r}\right)^{n^{\prime}} m^{\prime} \cos m^{\prime} \lambda \frac{\bar{P}_{n^{\prime} m^{\prime}}(\cos \Theta)}{\sin \Theta}=N_{n^{\prime} m^{\prime}}$, then Eq. (17) becomes (Heiskanen and Moritz 1967)

$$
\left\{\begin{array}{l}
\Delta \mathrm{g}=\frac{\mathrm{GM}}{\mathrm{r}^{2}}\left(\sum_{\mathrm{n}^{\prime}=2}^{\infty} \sum_{\mathrm{m}^{\prime}=0}^{\mathrm{n}^{\prime}} \mathrm{A}_{\mathrm{n}^{\prime} \mathrm{m}^{\prime}} \overline{\mathrm{C}}_{\mathrm{n}^{\prime} \mathrm{m}^{\prime}}^{*}+\sum_{\mathrm{n}^{\prime}=2}^{\infty} \sum_{\mathrm{m}^{\prime}=0}^{\mathrm{n}^{\prime}} \mathrm{B}_{\mathrm{n}^{\prime} \mathrm{m}^{\prime}} \overline{\mathrm{S}}_{\mathrm{n}^{\prime} \mathrm{m}^{\prime}}\right) \\
\xi=\frac{\mathrm{GM}}{\gamma \mathrm{r}^{2}}\left(\sum_{\mathrm{n}^{\prime}=2}^{\infty} \sum_{\mathrm{m}^{\prime}=0}^{\mathrm{n}^{\prime}} \mathrm{D}_{\mathrm{n}^{\prime} \mathrm{m}^{\prime}} \overline{\mathrm{C}}_{\mathrm{n}^{\prime} \mathrm{m}^{\prime}}^{*}+\sum_{\mathrm{n}^{\prime}=2}^{\infty} \sum_{\mathrm{m}^{\prime}=0}^{\mathrm{n}^{\prime}} \mathrm{E}_{\mathrm{n}^{\prime} \mathrm{m}^{\prime}} \overline{\mathrm{S}}_{\mathrm{n}^{\prime} \mathrm{m}^{\prime}}\right) . \\
\eta=\frac{\mathrm{GM}}{\gamma \mathrm{r}^{2}}\left(\sum_{\mathrm{n}^{\prime}=2}^{\infty} \sum_{\mathrm{m}^{\prime}=0}^{\mathrm{n}^{\prime}} \mathrm{M}_{\mathrm{n}^{\prime} \mathrm{m}^{\prime}} \overline{\mathrm{C}}_{\mathrm{n}^{\prime} \mathrm{m}^{\prime}}^{*}-\sum_{\mathrm{n}^{\prime}=2}^{\infty} \sum_{\mathrm{m}^{\prime}=0}^{\mathrm{n}^{\prime}} \mathrm{N}_{\mathrm{n}^{\prime} \mathrm{m}^{\prime}} \overline{\mathrm{S}}_{\mathrm{n}^{\prime} \mathrm{m}^{\prime}}\right)
\end{array}\right.
$$


The standard deviation of Earth's gravity potential coefficients are denoted as $\sigma_{\overline{\mathrm{C}}_{\mathrm{n}^{\prime} \mathrm{m}^{\prime}}}$ and $\sigma_{\overline{\mathrm{S}}_{\mathrm{n}^{\prime} \mathrm{m}^{\prime}}}$, which can be determined from the earth's gravitational model. Thus the covariance function of the gravity anomalies and the cross-covariance function between the gravity anomalies and the DOV components for two arbitrary datum points $\mathrm{P}$ and $\mathrm{Q}$ can be calculated according to the error propagation theory, then Eq. (18) becomes

$$
\left\{\begin{array}{l}
\operatorname{COV}\left(\Delta \mathrm{g}^{\mathrm{P}}, \Delta \mathrm{g}^{\mathrm{Q}}\right)=\frac{\mathrm{GM}}{\mathrm{r}_{\mathrm{P}}^{2}} \frac{\mathrm{GM}}{\mathrm{r}_{\mathrm{Q}}^{2}}\left(\sum_{\mathrm{n}^{\prime}=2}^{\infty} \sum_{\mathrm{m}^{\prime}=0}^{\mathrm{n}^{\prime}} \mathrm{A}_{\mathrm{n}^{\prime} \mathrm{m}^{\prime}}^{\mathrm{P}} \sigma_{\overline{\mathrm{C}}_{\mathrm{n}^{\prime} \mathrm{m}^{\prime}}}^{2} \mathrm{~A}_{\mathrm{n}^{\prime} \mathrm{m}^{\prime}}^{\mathrm{Q}}+\sum_{\mathrm{n}^{\prime}=2}^{\infty} \sum_{\mathrm{m}^{\prime}=0}^{\mathrm{n}^{\prime}} \mathrm{B}_{\mathrm{n}^{\prime} \mathrm{m}^{\prime}}^{\mathrm{P}} \sigma_{\overline{\mathrm{S}}_{\mathrm{n}^{\prime} \mathrm{m}^{\prime}}}^{2} \mathrm{~B}_{\mathrm{n}^{\prime} \mathrm{m}^{\prime}}^{\mathrm{Q}}\right) \\
\operatorname{COV}\left(\Delta \mathrm{g}^{\mathrm{P}}, \xi^{\mathrm{Q}}\right)=\frac{\mathrm{GM}}{\mathrm{r}_{\mathrm{P}}^{2}} \frac{\mathrm{GM}}{\gamma_{\mathrm{Q}} \mathrm{r}_{\mathrm{Q}}^{2}}\left(\sum_{\mathrm{n}^{\prime}=2}^{\infty} \sum_{\mathrm{m}^{\prime}=0}^{\mathrm{n}^{\prime}} \mathrm{A}_{\mathrm{n}^{\prime} \mathrm{m}^{\prime}}^{\mathrm{P}} \sigma_{\overline{\mathrm{C}}_{\mathrm{n}^{\prime} \mathrm{m}^{\prime}}}^{2} \mathrm{D}_{\mathrm{n}^{\prime} \mathrm{m}^{\prime}}^{\mathrm{Q}}+\sum_{\mathrm{n}^{\prime}=2}^{\infty} \sum_{\mathrm{m}^{\prime}=0}^{\mathrm{n}^{\prime}} \mathrm{B}_{\mathrm{n}^{\prime} \mathrm{m}^{\prime}}^{\mathrm{P}} \sigma_{\overline{\mathrm{S}}_{\mathrm{n}^{\prime} \mathrm{m}^{\prime}}}^{2} \mathrm{E}_{\mathrm{n}^{\prime} \mathrm{m}^{\prime}}^{\mathrm{Q}}\right) . \\
\operatorname{COV}\left(\Delta \mathrm{g}^{\mathrm{P}}, \eta^{\mathrm{Q}}\right)=\frac{\mathrm{GM}}{\mathrm{r}_{\mathrm{P}}^{2}} \frac{\mathrm{GM}}{\gamma_{\mathrm{Q}} \mathrm{r}_{\mathrm{Q}}^{2}}\left(\sum_{\mathrm{n}^{\prime}=2}^{\infty} \sum_{\mathrm{m}^{\prime}=0}^{\mathrm{n}^{\prime}} \mathrm{A}_{\mathrm{n}^{\prime} \mathrm{m}^{\prime}}^{\mathrm{P}} \sigma_{\overline{\mathrm{C}}_{\mathrm{n}^{\prime} \mathrm{m}^{\prime}}}^{2} \mathrm{M}_{\mathrm{n}^{\prime} \mathrm{m}^{\prime}}^{\mathrm{Q}}+\sum_{\mathrm{n}^{\prime}=2}^{\infty} \sum_{\mathrm{m}^{\prime}=0}^{\mathrm{n}^{\prime}} \mathrm{B}_{\mathrm{n}^{\prime} \mathrm{m}^{\prime}}^{\mathrm{P}} \sigma_{\overline{\mathrm{S}}_{\mathrm{n}^{\prime} \mathrm{m}^{\prime}}}^{2} \mathrm{~N}_{\mathrm{n}^{\prime} \mathrm{m}^{\prime}}^{\mathrm{Q}}\right)
\end{array}\right.
$$

Since the factors that affect the DOVs are complicated and the DOVs are influenced by unknown factors besides the measured gravity anomalies. In order to further improve the estimated DOVs using gravity anomalies along the ship route, one needs to update the results using the given value of DOVs measured on the mainland and island. The measured DOVs components include $\xi_{\mathrm{A}}^{0}, \eta_{\mathrm{A}}^{0}$ on the mainland and $\xi_{\mathrm{B}}^{0}, \eta_{\mathrm{B}}^{0}$ on the island. The DOVs components which are estimated by the remove-restore theory and gravity anomalies are $\xi_{\mathrm{A}}, \eta_{\mathrm{A}}$ on the mainland and $\xi_{\mathrm{B}}, \eta_{\mathrm{B}}$ on the island. Then the difference between $\xi_{\mathrm{A}}^{0}, \eta_{\mathrm{A}}^{0}, \xi_{\mathrm{B}}^{0}$, $\eta_{\mathrm{B}}^{0}$ and $\xi_{\mathrm{A}}, \eta_{\mathrm{A}}, \xi_{\mathrm{B}}, \eta_{\mathrm{B}}$ are $\Delta \xi_{\mathrm{A}}, \Delta \eta_{\mathrm{A}}, \Delta \xi_{\mathrm{B}}$ and $\Delta \eta_{\mathrm{B}}$, respectively. Supposing that the differences between the "true" value of the DOVs along the ship route and the restored DOVs components along the ship route are linear, the correction value of DOV components for the i-th segment along the ship route are $\Delta \xi_{i}=\Delta \xi_{\mathrm{A}}+\frac{\Delta \xi_{\mathrm{B}}-\Delta \xi_{\mathrm{A}}}{\mathrm{S}_{\mathrm{AB}}} \mathrm{S}_{\mathrm{Ai}}$ and $\Delta \eta_{\mathrm{i}}=$ $\Delta \eta_{\mathrm{A}}+\frac{\Delta \eta_{\mathrm{B}}-\Delta \eta_{\mathrm{A}}}{\mathrm{S}_{\mathrm{AB}}} \mathrm{S}_{\mathrm{Ai}}$ (Guo et al. 2013, 2014), in which $\mathrm{S}_{\mathrm{AB}}$ is the ship route distance between $\mathrm{A}$ and $\mathrm{B}, \mathrm{S}_{\mathrm{Ai}}$ is the distance between $\mathrm{A}$ and the $\mathrm{i}$-th segment along the ship route. Then the final value of the DOV components $\xi_{\mathrm{i}}^{0}$ and $\eta_{\mathrm{i}}^{0}$ for the $\mathrm{i}$-th segment of the ship route are $\Delta \xi_{\mathrm{i}}+\xi_{\mathrm{i}}$ and $\Delta \eta_{\mathrm{i}}+\eta_{\mathrm{i}}$.

\section{Case study}

\subsection{Practical case}

There are two given orthometric height datums in this case where SLZ station is located on the Qingdao coast and P004 station is located on the Caoyu Island (Fig. 3). The distance between these two datums are longer than $1000 \mathrm{~km}$. Here, we aim to connect the orthometric height of these two datum points using the proposed method. The ship is equipped with ship-borne GNSS and gravity meter. Starting from the SLZ station, we collected gravimetric and GNSS data along the ship route for about $1,222.933 \mathrm{~km}$. When the ship reached the P004 station, it makes a round voyage along the same ship route to return the SLZ station and also collects the gravimetric and GNSS data till the end of the voyage. To assess the accuracy, the height difference between the SLZ station and P004 station was measured beforehand with the precise spirit leveling method. 


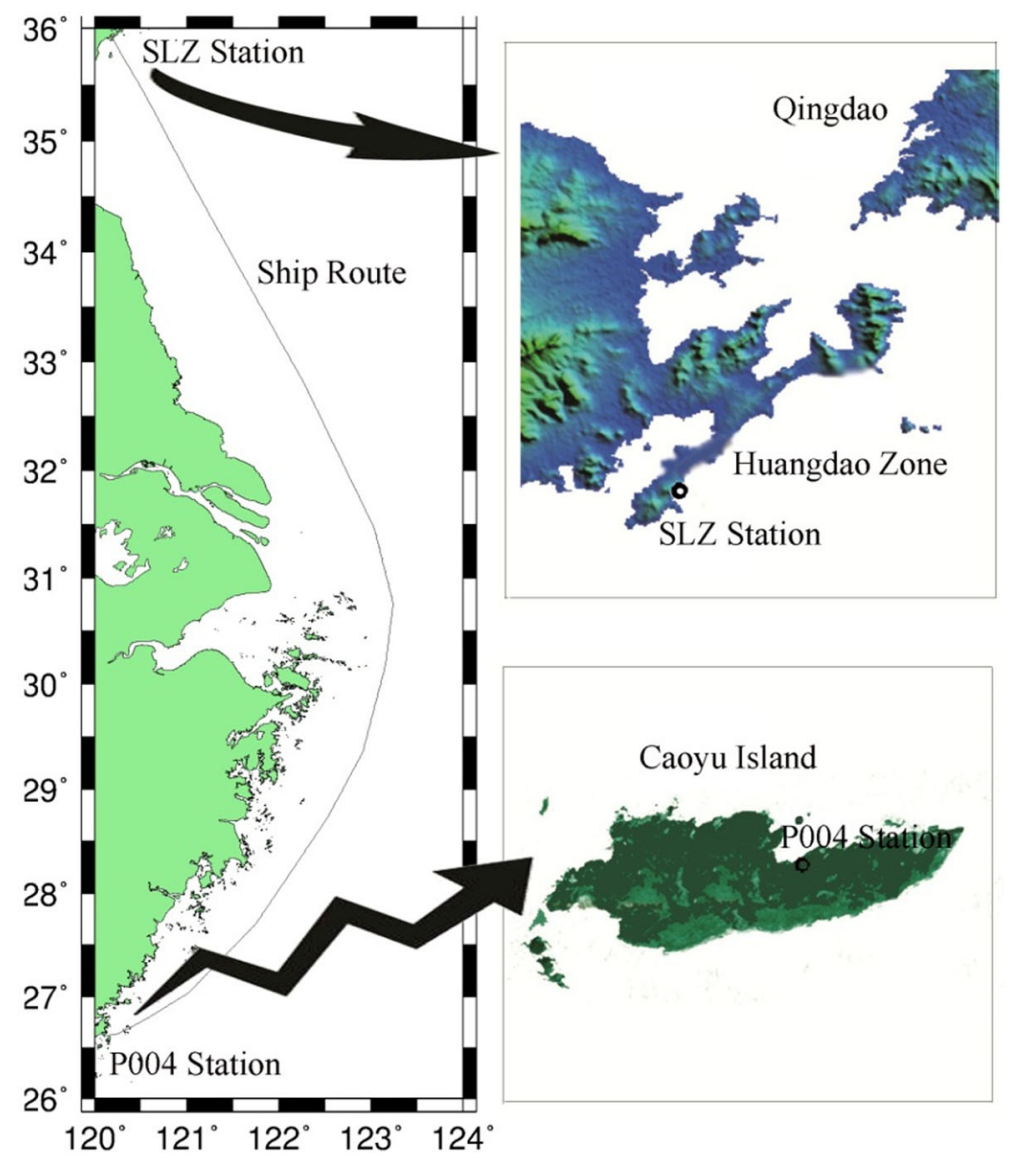

Fig. 3 Orthometric height connection along the ship route

Linear interpolation was used to process the ship-borne gravimetry and GNSS data to get the leaving and returning values at the same location of the ship route. The data processing of orthometric height connection across sea is shown in Fig. 4. According to the analysis of Sect. 2.3, the measured ship-borne gravimetry and GNSS data were segmented with the segment lengths of $2,2.5,5$ and $10 \mathrm{~km}$, respectively. One gravity value in the middle of each segmentation was chosen to represent the mean gravity value of this segment. So the ship route was divided into 610, 488, 244 and 122 segments, respectively.

The Earth gravitational model EGM2008 is used to compute the covariance and crosscovariance function in the estimation of the residual DOVs components along the ship route. The number of used residual gravity anomalies $\mathrm{j}$ is equal to the number of computed residual DOVs components $\mathrm{k}$ in a subgroup computation in Eq. (14). The values 4, 5, 6 and 7 are sequentially used for $\mathrm{k}$ in the residual DOVs components computation in a roundtrip, the results are shown in Table 2. 


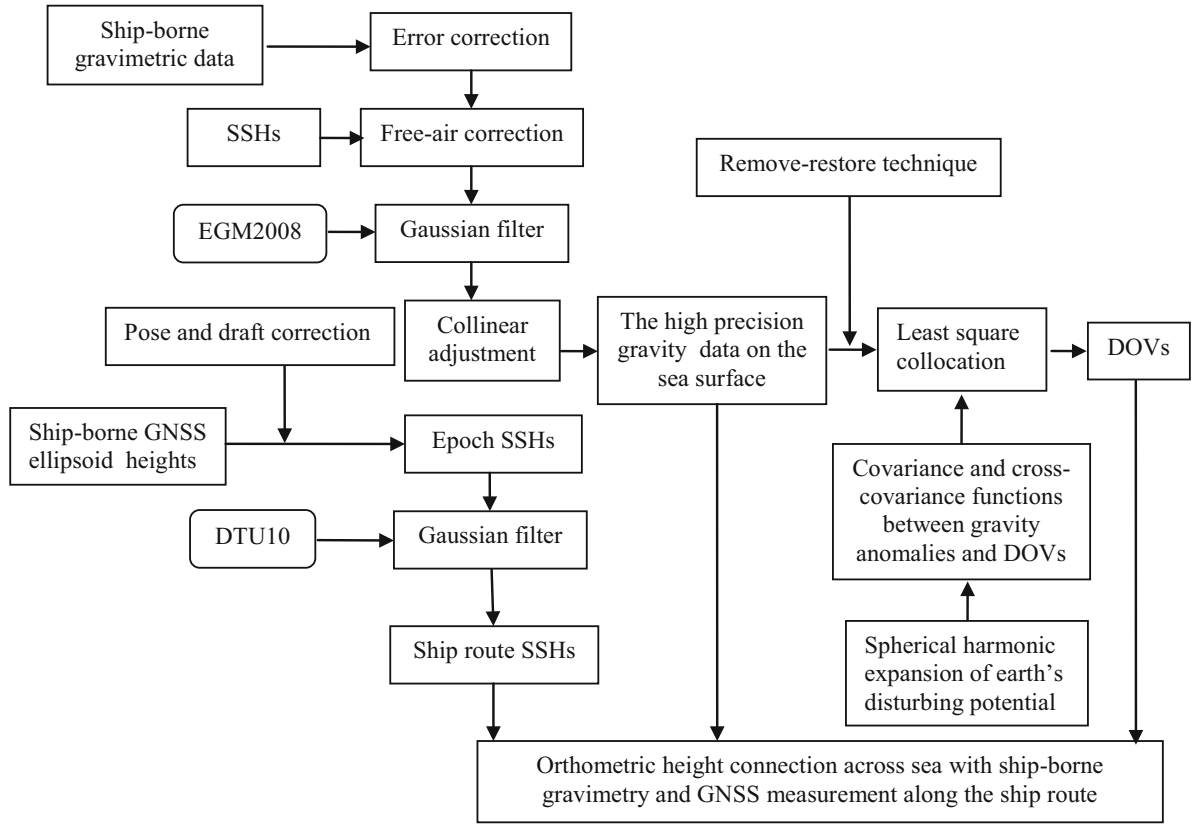

Fig. 4 The technology roadmap of orthometric height connection across sea

Table 2 Loop errors of height connection comparing with the precise spirit leveling method (unit in $\mathrm{mm}$ )

\begin{tabular}{llllll}
\hline $\begin{array}{l}\text { Length for each } \\
\text { segmentation }\end{array}$ & $\begin{array}{l}\text { Value of } \\
k \text { or } j\end{array}$ & $\begin{array}{l}\text { Loop } \\
\text { error }\end{array}$ & $\begin{array}{l}\text { Length for each } \\
\text { segmentation }\end{array}$ & $\begin{array}{l}\text { Value of } \\
k \text { or } j\end{array}$ & $\begin{array}{l}\text { Loop } \\
\text { error }\end{array}$ \\
\hline $10.0 \mathrm{~km}$ & 4 & -282.2 & & 4 & -285.6 \\
& 5 & -306.9 & & 5 & -539.0 \\
& 6 & -239.9 & $5 \mathrm{~km}$ & 6 & -372.2 \\
& 7 & -285.5 & & 7 & -558.3 \\
& 4 & -226.7 & & 4 & -306.2 \\
& 5 & -477.9 & & 5 & -296.8 \\
& 6 & -504.5 & $2 \mathrm{~km}$ & 6 & -381.1 \\
& 7 & -428.1 & & 7 & -416.2 \\
\hline
\end{tabular}

\subsection{Results and remarks}

Table 2 lists the loop errors of orthometric height connection for different segmentation lengths and $k$ values. Here the loop error means the difference between the connection results and the given leveling value. Table 2 shows that the loop errors are -296.8 to $-416.2,-226.7$ to $-504.5,-285.6$ to -558.3 and -239.9 to $-306.9 \mathrm{~mm}$, corresponding to the length of each segment 2.0, 2.5, 5 and $10 \mathrm{~km}$, respectively. The loop errors are relatively stable with different dimensions of covariance matrix when the segment length is $10 \mathrm{~km}$, and the difference of the maximum error and the minimum error is only $67 \mathrm{~mm}$. When the distance of each segmentation is $2.5 \mathrm{~km}$, the loop errors varied greatly with 
different dimensions of covariance matrix and the difference between the maximum error and the minimum error is up to $277.8 \mathrm{~mm}$. The accuracy of the loop error can achieve $-226.7 \mathrm{~mm}$ when the length of each segmentation is $2.5 \mathrm{~km}$ and $k$ value is 4 in this study.

Table 2 shows that the precision of height connection between datums across sea is affected by the segment lengths besides errors of the computational DOVs and ellipsoidal height differences along the ship route. The computational results are basically consistent with the analysis of optimal partition number in Sect. 2.3. The analysis of height connection across sea for $1000 \mathrm{~km}$ in Sect. 2.3 is conducted under the assumption that the measurements of all segments are independent and the errors of DOVs and ellipsoidal height differences are equal in each segmentation for the same segment length. Practically, the errors of measurements are slightly different in different places. Additionally, the covariance matrix with different dimensions will affect the precisions of computational DOVs and thus will affect the precisions of the connecting orthometric height. The computational results are different utilizing different dimensions of covariance matrix under the same segment length. The variation is relatively small with long segment length for different dimensions of covariance matrix, and vice versa.

\section{Conclusions}

The orthometric height difference between two datum points can be determined by the geoid height difference of the two datum points, which can be calculated based on the astronomical leveling principle. The key to connect the orthometric height across sea is the precise DOVs determination. Traditionally, the astronomical geodetic method is used to measure DOVs over land, but the process cannot be carried out on the sea surface because of the dynamic sea environment. The DOVs can be measured precisely on the mainland and island and also the high precision gravimetric data along the ship route on the sea surface can be measured by the ship-borne gravimeter. The remove-restore technique is used to remove the middle- and low-frequency parts of the gravity anomalies from the processed sea surface gravity anomalies along the ship route. The residual DOVs which are estimated from high frequency of the gravity anomalies in conjunction with model DOVs restore the DOVs. The restored DOVs are updated by the measured high precision DOVs located on the mainland and island in order to further improve the accuracy of DOVs along the ship route. The astronomical leveling principle is used to determine the geoid undulation difference between the mainland and island height datums. The relationship between the difference of the geoid undulation, orthometric height difference and ellipsoidal height difference are used to determine the orthometric height datum of the island. Finally, we connect the height datums.

In this contribution, the formula of orthometric height connection across sea is derived based on the astronomical leveling principle. The gravity anomalies and GNSS data are measured with ship-borne gravity meter and GNSS instruments. A round trip following the shortest route between mainland and island is made for the improvement of the accuracy of the ship-borne gravities and GNSS ellipsoidal height. The Gaussian filter is used to remove the data noise which is mainly caused by wind or wave and reduce the GNSS height to sea level height and the gravities are reduced to the mean sea level. Through the error propagation analysis, the effect of DOVs error and ellipsoidal height difference error is very important for the height connection across sea. To improve the accuracy of DOVs along the ship route, the remove-restore technique and LSC method are used. The co-variance of 
gravity anomalies and cross-covariance function between gravity anomalies and DOVs are derived from the disturbing potential spherical harmonic expansion. Another important factor for the accuracy of the orthometric height connection is the partition number. Through analysis 122, 244, 488 and 610 are chosen respectively for partition number in the test. The number of used residual gravity anomalies $j$ and the number of computed residual DOV components of $k$ in a computation subgroup in Eq. (14) are equal to each other in the practical test. The values of 4, 5, 6 and 7 are sequentially used for $k$ in the residual DOV components computation along the ship route in a round voyage. The astronomical leveling principle is used to determine the difference of the geoid undulations between the mainland and island height datums. The orthometric height of datum point $\mathrm{B}$ on island is determined according to the relationship between the geoid undulation difference, orthometric height difference and ellipsoidal height difference of datum points A and B. As an example, the orthometric height datum point on Qingdao coast in Shandong Province of China is connected to the datum point on Caoyu Island in Fujian Province of China. The ship route distance between the two locations is about $1,222.933 \mathrm{~km}$. The results indicate that this method is efficient.

Acknowledgments We thank anonymous reviewers for their helpful comments and suggestions. This study is supported by the National Natural Science Foundation of China (Grant No. 41374009), the Shandong Natural Science Foundation of China (Grant No. ZR2013DM009), the Basic Science and Technology Project of China (Grant No. 2015FY310200), and the SDUST Research Fund (Grant No. 2014TDJH101).

\section{References}

Andersen OB (2010) The DTU10 gravity field and mean sea surface. In: The 2nd international symposium of the gravity field of the earth (IGFS2), Fairbanks

Burša M, Kouba J, Kumar M, Müller A, Raděj K, True SA, Vatrt V, Vojtíšková M (1999) Geoidal geopotential and world height system. Stud Geophys Geod 43(4):327-337. doi:10.1023/A: 1023273416512

Burša M, Kouba J, Müller A, Raděj K, True SA, Vatrt V, Vojtíšková M (2001) Determination of geopotential differences between local vertical datums and realization of a world height system. Stud Geophys Geod 45(2):127-132. doi:10.1023/A:1021860126850

Burša M, Kenyob S, Kouba J, Šíma Z, Vatrt V, Vojtíšková M (2004) A global vertical reference frame based on four regional vertical datums. Stud Geophys Geod 48:493-502. doi:10.1023/B:SGEG.0000037468. 48585.e6

Fei ZL, Sideris MG (2001) GPS leveling and the second geodetic boundary value problem. In: Sideris MG (ed) Gravity, geoid, and goedynamics 2000. Springer-Verlag, Berlin, pp 341-346

Gerlach C, Rummel R (2013) Global height system unification with GOCE: a simulation study on the indirect bias term in the GBVP approach. J Geod 87:57-67. doi:10.1007/s00190-012-0579-y

Goldan HJ, Seeber G (1994) Precise tide gauge connection to the island of Helgoland. Mar Geod 17(2):147-152. doi:10.1080/15210609409379721

Guan ZL, Ning JS (1981) Earth shape and its exterior gravity field. Surveying and Mapping Press, Beijing (in Chinese)

Guo JY, Chen YN, Liu X, Zhong SX, Mai ZQ (2013) Route height connection across the sea by using the vertical deflections and ellipsoidal height data. China Ocean Eng 27(1):99-110. doi:10.1007/s13344013-0009-9

Guo J, Liu X, Chen Y, Wang J, Li C (2014) Local normal height connection across sea with ship-borne gravity and GNSS techniques. Mar Geophy Res 35:141-148. doi:10.1007/s11001-014-9216-X

Heck B, Rummel R (1990) Strategies for solving the vertical datum problem using terrestrial and satellite geodetic data. In: Sünkel H, Baker T (eds) Seasurface topography and the geoid. Springer, Berlin, Germany, pp 116-128

Heiskanen W, Moritz H (1967) Physical geodesy. Freeman, San Francisco

Huang MT, Zhai GJ, Guan Z, Ouyang YZ, Liu YC (2005) Determination and applications of marine gravity field. Surveying and Mapping Press, Beijing (in Chinese) 
Kumar M, Burke KJ (1998) Realizing a global vertical datum with the use of geoid. In: Vermeer M, Ádám J (eds) Proceedings of the second continental workshop on the geoid in Europe, Report 98:4, Finnish Geodetic Institute, Masala, pp 87-94

Li JC, Jiang WP (2001) Height datum transference within long distance across sea. Geomat Inf Sci Wuhan Univ 26(6):514-517 (in Chinese)

Li F, Chen W, Yue JL (2003) On solution and application of GPS/gravity boundary value problem. Chin J Geophys 46(5):595-599. doi:10.1002/cjg2.405

Liibusk A (2013) Precise hydrodynamic leveling using pressure gauges with application to improvement of the Estonian national leveling network. PhD thesis, Estonian University of Life Sciences

Mather RS, Rizos C, Morrison T (1978) On the unification of geodetic leveling datums using satellite altimetry. NASA Technical Memorandum, NASA-TM-79533

Nahavandchi H, Sjöberg LE (1998) Unification of vertical datums by GPS and gravimetric geoid models using modified Stokes formula. Mar Geod 21(4):261-273. doi:10.1080/01490419809388142

Pan M, Sjöberg LE (1998) Unification of vertical datums by GPS and gravimetric geoid models with application to Fennoscandia. J Geod 72(2):64-70. doi:10.1007/s001900050149

Pavlis NK, Holmes SA, Kenyon S, Factor JK (2012) The development and evaluation of the Earth gravitational model 2008. J Geophys Res 117:B04406. doi:10.1029/2011JB008916

Pouttanen M (1999) Use of GPS in unification of vertical datums and detection of levelling network errors. In: Lilje M (ed) Proceedings of geodesy and surveying in the future: the importance of heights, LMV Report 1999:3, National Land Survey, Gävle, pp 301-312

Rapp RH, Cruz J (1986) The representation of the earth's gravitational potential in a spherical harmonic expansion to degree 250, Report 372, Department of Geodetic Science, Ohio State University, Columbus

Rapp RH, Rummel R (1975) Methods for the computation of detailed geoids and their accuracy, Report 233, Department of Geodetic Science, Ohio State University, Columbus

Rummel R (2012) Height unification using GOCE. J Geod Sci 2(4):355-362. doi:10.2478/v10156-011$0047-2$

Rummel R, Teunissen PJG (1988) Height datum definition, height datum connection and the role of the geodetic boundary value problem. Bull Géod 62(4):477-498. doi:10.1007/BF02520239

Sacerdote F, Sanso F (1989) On the analysis of the fixed boundary gravimetry BVP. In: The second HotineMarussi symposium on mathematical geodesy, Pisa

Xu HZ, Bao LF, Lu Y (2009) Precise transfer of height datum across ocean with gravimetric potential difference method. Institute of Geodesy and Geophysics, CAS, Wuhan (in Chinese)

Yu JH, Jekeli C, Zhu M (2003) The analytical solutions of the Dirichlet and Neumann boundary value problems with ellipsoidal boundary. J Geod 76(11):653-667. doi:10.1007/s00190-002-0271-8

Zhang L, Li F, Chen W, Zhang C (2009) Height datum unification between Shenzhen and Hong Kong using the solution of the linearized fixed-gravimetric boundary value problem. J Geod 83(5):411-417. doi:10.1007/s00190-008-0234-9 